\title{
Blended Learning of Management Courses Based on Learning Behaviour Analysis
}

\author{
https://doi.org/10.3991/ijet.v16i09.22741 \\ Yang Liu \\ Chongqing Technology and Business Institute, Chongqing, China \\ Kris ocean@163.com
}

\begin{abstract}
The development of information and network technologies fundamentally changes the life, learning, and mindset of students. Teaching informatization is a key content of modern education, and the main direction of teaching reform. In this context, blended learning becomes the inevitable trend of teaching form development. Currently, the teaching of management courses in China faces several problems: the lack of overall planning of teaching design and organization, the low learning interest among students, and the failure of cultivating students' comprehensive quality. To improve the teaching effect of management courses, this paper carries out a questionnaire survey on the learning behaviours of college students and their needs for blended learning. The survey results show that: the students are not accustomed to pre-class preview and after-class review; most students have the awareness and ability to solve problems with online information; most students are willing to accept blended learning, and expect teachers to provide teaching resources in the form of videos and electronic documents. On this basis, the authors developed an evaluation index system for blended learning according to the constituent factors of this teaching model, and designed a blended learning model for management courses through learning behaviour analysis. The blended learning model was divided into three phases: pre-class, in-class, and after-class, and the online/offline teaching activities of teachers and students were detailed in each phase. To verify its application effect, the blended learning model was verified through comparative analysis from two aspects: learning behaviour and learning effect. The results show that blended learning model achieves better learning participation, and teaching/learning effect than traditional teaching model, and helps to enhance the knowledge and comprehensive ability of the students. The research provides a reference for further research and application of blended learning in management courses, and boasts great theoretical and practical values.
\end{abstract}

Keywords - Learning behaviour analysis, blended learning, constituent factors, evaluation index system, application effect 


\section{Introduction}

The advent of the Internet+ Education era has changed people's learning methods, the society has proposed new requirements for the cultivation of talents, and the blended teaching mode has emerged per the requirements of the times in this context. Blended teaching mode is a new form of informatized teaching that integrates online teaching with the traditional classroom teaching, it reconstructs the teaching process, makes full use of high-quality resources and tools, and absorbs both the advantages of online teaching and traditional classroom teaching; and it is very important for stimulating students' interest in learning, enhancing their comprehensive quality, and improving the quality of teaching [1]. Now blended teaching mode has become a new direction for education reform, and the research on blended teaching mode has become a hotspot that has received extensive attention from field scholars.

Some foreign researchers divided the blended teaching mode into three types: ability-driven type, attitude-driven type, and skill-driven type, and explained the three mode types in detail [2]. Some constructed a four-stage blended teaching mode through research, and some researched the construction process and precautions of blended teaching mode [3]. In China, studies on blended teaching mode started relatively late, but still achieved a few research results in aspects such as connotation, supporting idea, environmental composition, teaching tool, and teaching method, and a variety of blended teaching modes have been constructed [4]. By reviewing these literatures, we can see that the research on blended teaching mode has attracted great attention both at home and abroad, and fruitful theoretical research results have been obtained. However, most of the existing studies start from teaching mode itself and have not considered the connection between student behaviour with the blended teaching mode. As we all know, students' learning behaviour (emotions, attitudes, participation, etc.) is one of the most important factors that can influence the teaching effect [5]. Therefore, out of such concerns, this paper starts from the perspective of students' learning behaviour and conducts analysis and research on the blended teaching mode for management courses based an analysis of the learning behaviour.

\section{Investigation and Analysis of Student Learning Behaviour}

In order to be able to design a blended teaching mode that can fully meet the actual needs of students and effectively improve the teaching effect of management courses, at first, our study conducted a questionnaire survey on the learning habits of Chinese college students and their requirements for blended teaching mode. The survey selected college students from 5 Chinese colleges in Hubei Province as respondents and sent out and collected a total of 950 questionnaires, of which 937 were valid, with an effective rate of $98.6 \%$. After a careful analysis of the survey results, the following conclusions were obtained. 


\subsection{Analysis of student learning behaviour}

Figure 1 gives the statistics of students' self-study situations before class. According to the figure, most students do not carry out autonomous learning before class, and further investigation suggested that they are not willing to study by themselves before class because they do not know what to learn, so they just wait for the class and listen to what the teachers say; only $18 \%$ of the students often or occasionally conduct selfstudy before class, but still these students just browse books and some may search online for the subjects they are interested in.

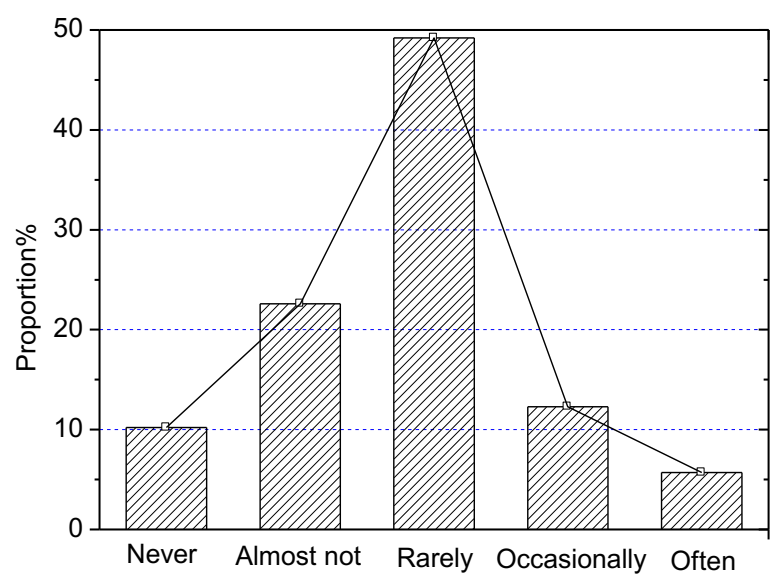

Fig. 1. Statistics of students' self-study situation before class

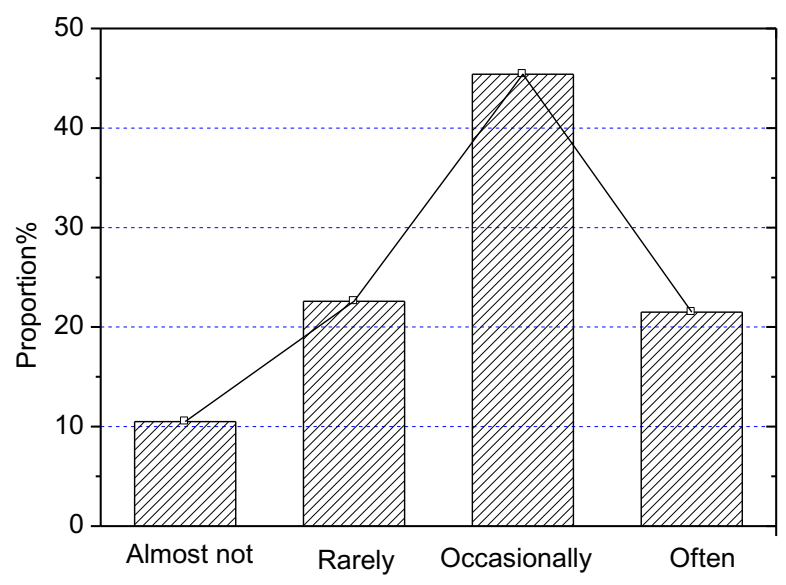

Fig. 2. Statistics of students' review and learning consolidation situations after-class

Figure 2 gives the statistics of students' after-class review and learning consolidation situations. According to the figure, $33.1 \%$ of students hardly or rarely review or 
consolidate their knowledge after class, and further investigation suggested that most of the students' after-class review and learning consolidation behaviours are due to the homework and learning tasks assigned by teachers, and this indicates that students' autonomous learning ability is weak.

Table 1 shows the methods for students to access to solutions or knowledge when they encounter problems in their lives, according to the figure, most students choose to find solutions online, indicating that they do have the awareness and ability to use the Internet to find information and resources to solve problems.

Table 1. Methods for students to access to solutions or knowledge

\begin{tabular}{|l|c|}
\hline \multicolumn{1}{|c|}{ Access to solutions or knowledge } & Proportion \\
\hline Search online & $85 \%$ \\
\hline Go to the library to check materials & $32 \%$ \\
\hline Discuss with classmates or friends & $28 \%$ \\
\hline Ask teachers & $44 \%$ \\
Others & $12 \%$ \\
\hline
\end{tabular}

\subsection{Students' requirements for blended teaching mode}

Figure 3 shows the statistics of students' willingness to adopt blended teaching mode. According to the figure, most students are willing to adopt the online-offline blended teaching mode and they hope this new mode can increase their professional knowledge, enhance their ability, and make the teaching more flexible and vivid, not just the dull and drowsy lecturing. In addition, $7.6 \%$ of students expressed unwillingness to adopt the blended teaching mode, some students worry that online learning would increase their learning burden after class and affect their after-school life, and some students show no expectation to any teaching mode because their own learning willingness is low.

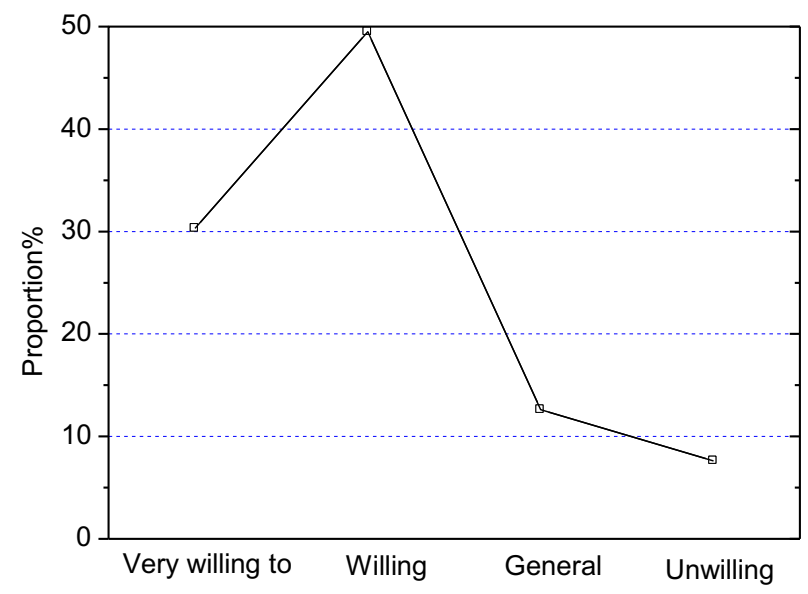

Fig. 3. Statistics of students' willingness to adopt blended teaching mode 
In the survey statistics of the teaching methods that students hope teachers to adopt, the top five are: cooperative inquiry method, problem-based learning method, project teaching method, lecture method and self-directed learning method, as shown in Table 2, the results indicate that, during the teaching process, teachers should adopt various teaching methods for different teaching content so as to trigger students' interest in learning and cultivate their comprehensive ability.

Table 2. Statistics of teaching methods students hope teachers to adopt

\begin{tabular}{|l|c|}
\hline \multicolumn{1}{|c|}{ Teaching method } & Proportion \\
\hline Cooperative inquiry & $85.2 \%$ \\
\hline Problem-based learning & $76.5 \%$ \\
\hline Project teaching method & $65.7 \%$ \\
\hline Lecture method & $48.3 \%$ \\
\hline Self-directed learning & $36.2 \%$ \\
\hline
\end{tabular}

Teaching resources are the basis for the development of blended teaching mode, and they have an important guiding role for students' online and offline learning. Figure 4 shows the survey results of students' requirements for teaching resources under the blended teaching mode, according to the figure, more than $90 \%$ of students prefer video resources. These students think that the role of video resources is just the same as that of teachers' lectures in class, and they can replay or pause the video at wills when they encounter difficulties, which is quite convenient for their learning. Besides, PPT and other electronic documents are also very popular among students. Therefore, when adopting blended teaching mode, teachers should provide students with various and sufficient e-learning resources according to their learning requirements.

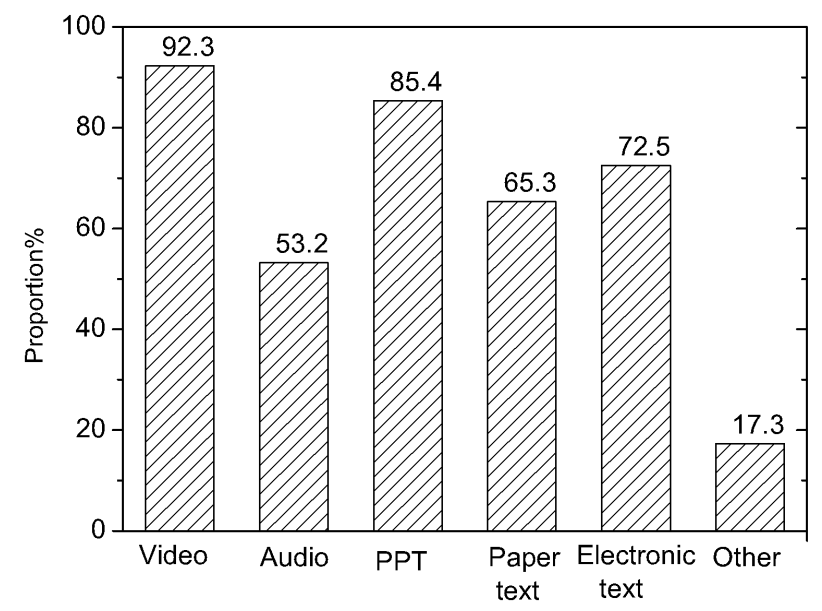

Fig. 4. Statistics of students' requirements for teaching resources 


\section{Design of a Blended Teaching Mode for Management Courses Based on Learning Behaviour Analysis}

\subsection{Constituent elements of the blended teaching mode}

A blended teaching mode is a complex system composed of a series of elements, these elements, together with the interactions among the elements, form the operating mechanism of the blended teaching mode [6]. The constituent elements of the blended teaching mode can provide a framework and specific references for the design and implementation of the blended teaching mode.

1. Teaching objectives: In simple words, teaching objectives are the learning results of students expected to be achieved in the teaching activities. Teaching objectives can be divided into three levels: education achievement objectives, curriculum objectives and classroom teaching objectives [7]. Teaching objectives point out the direction of teaching activities, and teaching activities are carried out with the achievement of teaching objectives as the centre. Correct and appropriate teaching objectives are helpful to improving the effectiveness of teaching activities.

The formulation of teaching objectives of blended teaching mode should be based on the requirements of the times and the characteristics of courses and learners, it should take the cultivation of students' interest, knowledge, and ability as the starting point, and be able to reflect the overall direction of the subject to a certain extent; moreover, the teaching objectives must be specific, clear, and operable [8]. The teaching objectives of blended teaching mode are not static, they should be determined according to the curriculum structure, course characteristics, teaching content, and specific teaching methods of subjects.

2. Operating procedures: All teaching modes have a relatively fixed framework and operating procedures, namely the specific links of the teachers' teaching activities and the specific methods of each link, such as how the teachers introduce new lessons, how to explain knowledge points, what teaching methods and tools are used. But it doesn't mean that the operating procedures are absolutely fixed, they will change constantly with the actual situations of teaching objectives, content, modes, methods, and students' learning status [9].

The operating procedures of blended teaching mode can be summarized into two parts: online learning and offline learning. Online learning is mainly achieved depending on online teaching platforms, including teachers' preparation of teaching resources before class, and students' preview before class and review after class. Offline learning is mainly for teachers and students to exchange and discuss about the learning content in the classroom; it can be subdivided into three learning stages: pre-class (online) learning stage, in-class (offline) learning stage, and after-class (offline) learning stage [10].

3. Realization conditions: Teachers, students, time, space, technology, environment, are all conditional factors for the realization of teaching mode. Any teaching mode can be effective only under certain conditions, and these conditional factors are the guarantee for the realization of teaching objectives [11]. For the realization condi- 
tions of blended teaching mode, in addition to the realization conditions that are the same as those of traditional teaching mode, the corresponding technical conditions are also a necessity, that is, the online teaching platform. The smooth implementation of blended teaching mode requires operable, personalized, interactive, and stable teaching platforms. Under the blended teaching mode, the roles of teachers and students would have important changes, students would take the dominant role in class, and teachers become the organizers, guides and collaborators of the class; moreover, the teaching methods would transform from the traditional indoctrination-style teaching to interactive communication, and the teaching sites would change from classrooms to online-offline sites. One last thing, a sound organization and management method is the prerequisite and basis for ensuring the effective implementation of blended teaching.

4. Teaching evaluation: Teaching evaluation is the process of making judgments on the actual or potential value of teaching activities. It has the functions of diagnosing teaching problems, providing feedback information, regulating teaching direction, and examining teaching effect. The goal of teaching evaluation is to gradually improve the teaching activities and promote the development of learners, therefore, teaching evaluation is an indispensable and important part of teaching activities [12]. In the traditional teaching evaluation mode, the purpose of evaluation is only to examine the degree to which students have reached the teaching objectives and the final exam results are generally used to evaluate the learning effect of students and the teaching level of teachers. However, with the continuous advancement of education and the progress of teaching reforms, teaching concepts and teaching methods have undergone major changes, and the evaluation concepts and modes have also transformed accordingly.

Compared with traditional teaching, blended teaching mode has undergone dramatic changes in teaching content, teaching methods, teaching tools, teaching space, teaching time, and other aspects, therefore, the traditional evaluation index system should not be used to evaluate the blended teaching mode. According to the operating procedures of the blended teaching mode, students' learning is divided into two parts: online learning and offline learning. Therefore, the evaluation index system should also include both online and offline evaluations, and the content of the evaluation should include soft-factor indicators of the various abilities and qualities of students (such as emotions, attitudes, and behaviours) during the specific learning process, as well as students' final learning results (such as homework completion and test scores). In order to give comprehensive evaluation of learners and transform teaching evaluation from "knowledge-based" to "knowledge+abilitybased", this paper constructed a blended teaching mode evaluation index system [13], as shown in Figure 5. 


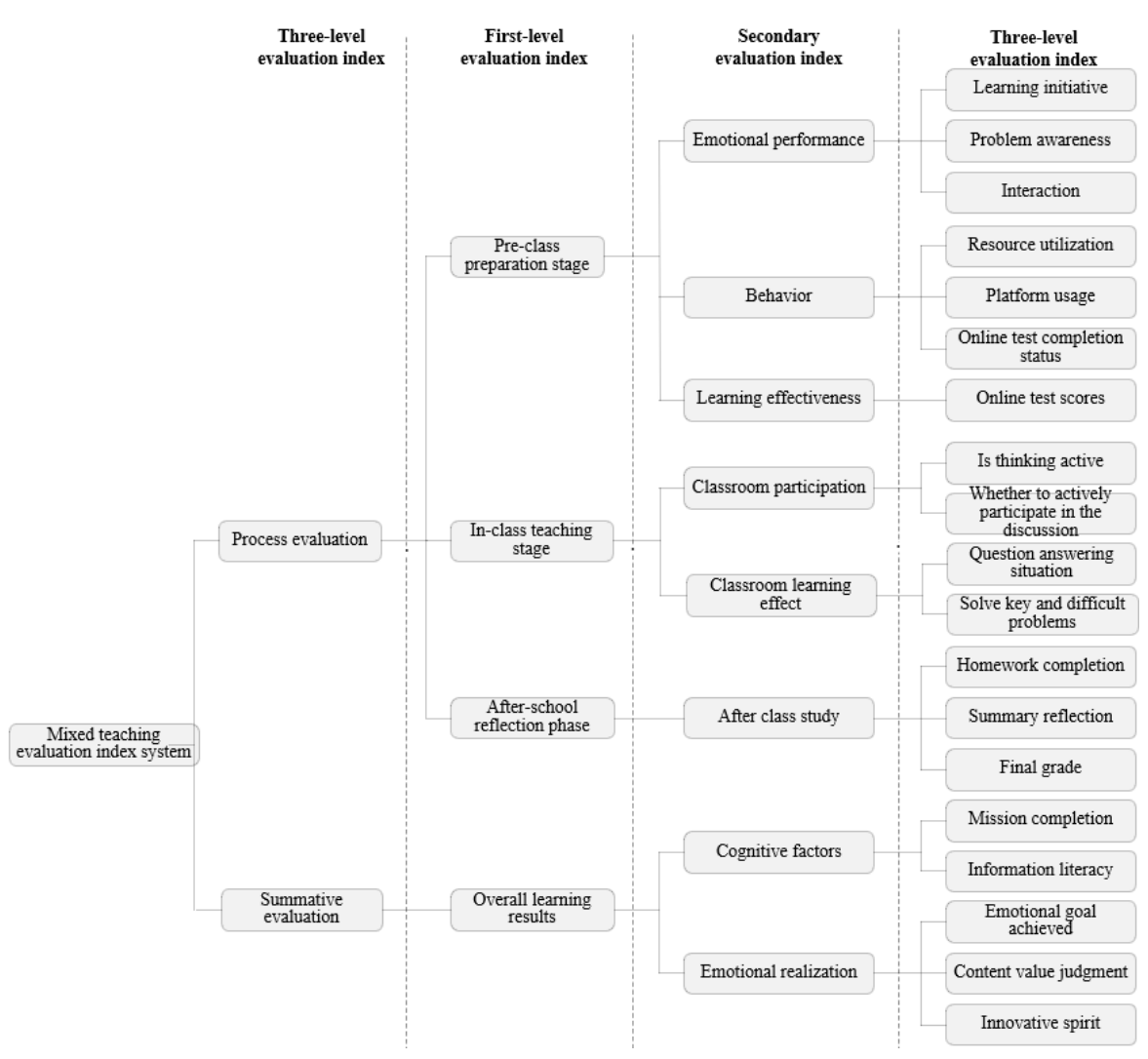

Fig. 5. The blended teaching mode evaluation index system

\subsection{Design of the proposed mode based on learning behaviour analysis}

Based on the constituent elements of blended teaching mode and the survey and analysis results of students' learning behaviour, this paper designed a blended teaching mode for management courses according to the design principles of integration, openness, interaction, and collaboration [14], as shown in Figure 6.

1. Before class - Teaching preparation stage: Teaching preparation is the initial stage of teaching and learning. At this stage, a series of learning and inquiry processes are carried out around the teaching objectives and teaching content. This stage contains three parts: teacher preparation, student preview, and teacher-student interaction, Figure 7 shows the flow of the teaching preparation stage [15].

Teacher preparation: Teaching design is the most important link in teaching. To teach a course, firstly, teachers must first determine the status and role of the course in the subject system, determine the knowledge level and behavioural results that students should achieve through the learning of the course, and determine the teaching objectives of each unit based on the course objectives, and these are the starting point 
and the end point of teaching design. Secondly, teachers should analyse the teaching content, conduct in-depth research on the teaching materials, and integrate and expand the teaching content in the teaching materials according to the characteristics of the subject and the cognition level of the learners. Thirdly, teachers should analyse the learning status of students, learning status analysis and teaching content analysis should be carried out synchronously. Learning status analysis means to analyse the learner's social and cultural environment, current knowledge level, learning attitude, learning methods, learning requirements, and cognition laws and characteristics, etc. Only when learners have a more thorough understanding can the blended teaching mode provide students with abundant online learning resources, and use their preferred teaching methods to stimulate their enthusiasm for learning. Fourthly, teachers should integrate the teaching resources, create meaningful learning environment, and provide rich online resources for students based on teaching content and the internal demands of students. Specifically, the resources include three categories: basic knowledge, integrated knowledge, and expanded knowledge; the teaching resources should be systematic, autonomous, open, and linked, and the forms of the resources could be video, PPT, micro-video, online test questions, and mind maps, etc. The rich online resources could provide convenience for students to learn courses at anytime, anywhere, trigger their interest in learning, and improve the efficiency of pre-class learning. Finally, in order to promote students' autonomous learning and provide guidance for students' online learning, teachers should design autonomous learning tasks and formulate specific regulations and requirements for the tasks and objectives of students' online learning.

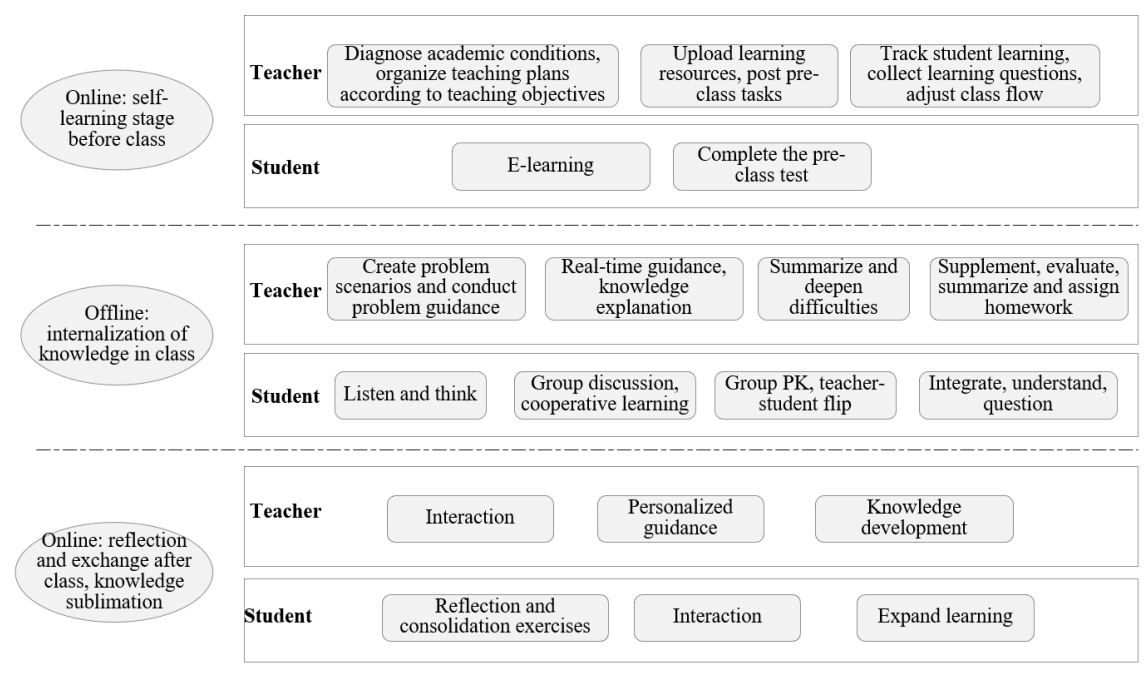

Fig. 6. The blended teaching mode for management courses based on learning behaviour analysis 


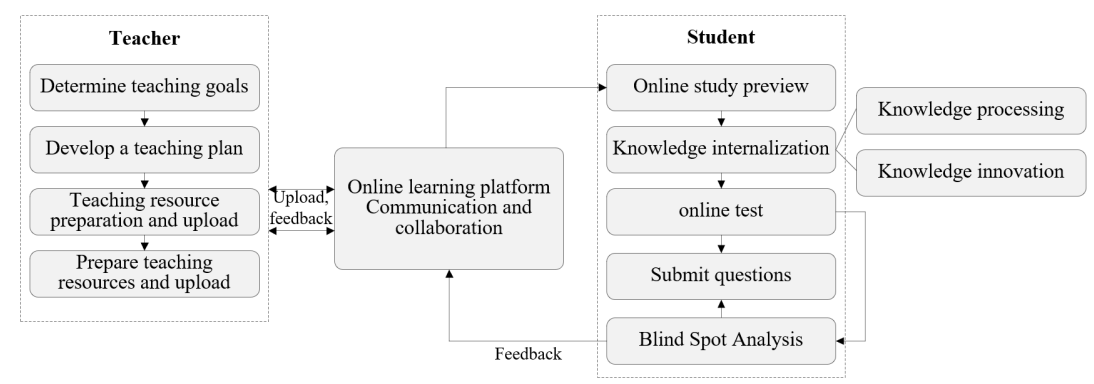

Fig. 7. Flow of the teaching preparation stage before class

Student preview. Before class, students take the learning tasks issued by teachers as the reference and use various teaching resources provided by teachers via online learning platforms to complete the pre-class preview tasks. They can also go online or go to the library by themselves to find more information to improve their understanding of the knowledge points. After finishing self-study, students can test their learning effect using online test questions assigned by teachers, and return to the online teaching platforms to fill in their blind spots and knowledge gaps; for more doubts and questions, they can use online communication platforms or social networking software (such as QQ, WeChat, Weibo) to communicate with teachers and other students; for unresolved problems or controversial issues, they can left them for in-depth discussions with teachers in class. Through the autonomous online self-study before class, students can not only improve their comprehensive ability in information organization, processing, and teamwork, but also build their own knowledge structure system and realize the reorganization, renewal, and internalization of knowledge.

Teacher-student interaction. Forming benign teacher-student and student-student interactions has always been one of the important measures to improve teaching efficiency. Under traditional teaching mode, the effect of such interactions is not optimistic; under the blended teaching mode, the Internet seems to separate teachers and students, but it actually shortens the distances between people and resources, between students and teachers, and between students and students, and they can use online platforms to discuss and communicate according to their own needs at any time, which has broken the time and space limitations of traditional teaching.

2. In class - the implementation stage of classroom teaching: After the pre-class preparation stage is over, teachers and students return to the traditional classroom face-to-face teaching link, but different from the traditional teaching mode, under the blended teaching mode, students have already had a certain understanding and mastery of the knowledge to be learnt, and they come to the class with questions; therefore, the roles and status of teachers and students in the classroom have changed greatly, students take the dominant role in the classroom, they bring the doubts and questions they encountered during pre-class self-study and communicate and discuss with teachers and other students. Also, the role of teachers has changed from the classroom manager and leader to the organizer, developer, communicator, and guide of the course. Teachers are responsible for listening to the 
problems encountered by students and giving guidance to the content to be discussed between students, when necessary, teachers will also participate in the discussion; the in-class teaching focuses on solving the problems encountered by students during pre-class self-study, and the teaching is more targeted. The entire teaching process is based on the dialogue between teachers and students and their joint discussion, and both parties have participated in the transmission, exchange, and feedback of information. It should be noted that in the teaching process, teachers should take the content of online teaching resources as the carrier, and adopt diverse teaching methods such as leading students to ask questions, or cooperative communication to help students master basic knowledge online, explore knowledge offline, study expanded knowledge, and realize the internalization of knowledge. After in-class teaching is completed, teachers should give targeted evaluations of students' learning behaviour and learning effect through teacher evaluation, student self-evaluation and student mutual evaluation; students should summarize the key knowledge points, difficult knowledge points, and blind spots of knowledge and reflect on whether their learning methods are appropriate, and these are helpful for them to carried out after-class review and knowledge expansion activities. In addition, teachers should also assign hierarchical homework assignments according to the learning characteristics of students in class, so that students can complete them after class. Figure 8 gives the flow of in-class teaching implementation stage [16].

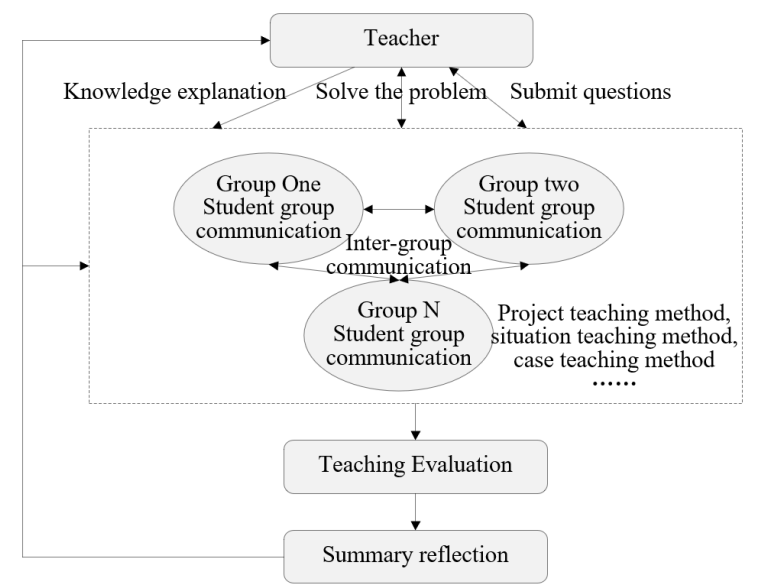

Fig. 8. Flow of in-class teaching implementation stage

3. After class - Reflection, exchange, and knowledge sublimation: After classroom teaching is completed, teachers need to summarize and reflect on the deficiencies in the teaching design and teaching process based on students' learning behaviour and learning effect, adjust the teaching content and teaching methods in time, and prepare for the next class. At the same time, teachers should check students' homework completion situations via online interaction platforms, communicate with students about the teaching content and coursework, and give special guid- 
ance for individual students; moreover, teachers can also propose expanded questions appropriately according to student communication and homework completion situations, and let students perform autonomous and inquiry learning by themselves.

Students need to conduct self-summary and self-reflection based on the evaluations given by teachers and other students in the class, and use the knowledge consolidation exercises provided by online learning platforms or the homework assigned by teachers to consolidate the knowledge they learnt. For doubts and problems students encountered and discussed with teachers and other students, they can conduct extended learning based on the teaching content according to their own learning status to achieve the sublimation of knowledge.

\section{$4 \quad$ Analysis of Students' Learning Behaviour and Learning Effect Under the Blended Teaching Mode for Management Courses}

To verify the effectiveness of the proposed blended teaching mode for management courses, our study selected 4 classes of the business management major in a Chinese college as the research objects. All 4 classes had the "Management science" course, 2 of the 4 classes were taken as the test classes (test group, 70 students) to adopt the blended teaching mode, and the other 2 classes were taken as the control classes (control group, 72 students) to adopt the traditional teaching mode, but the students were required to conduct online learning by themselves. After that, the students' learning behaviour and learning effect under the two teaching modes were compared and analysed.

\subsection{Analysis of student learning behaviour}

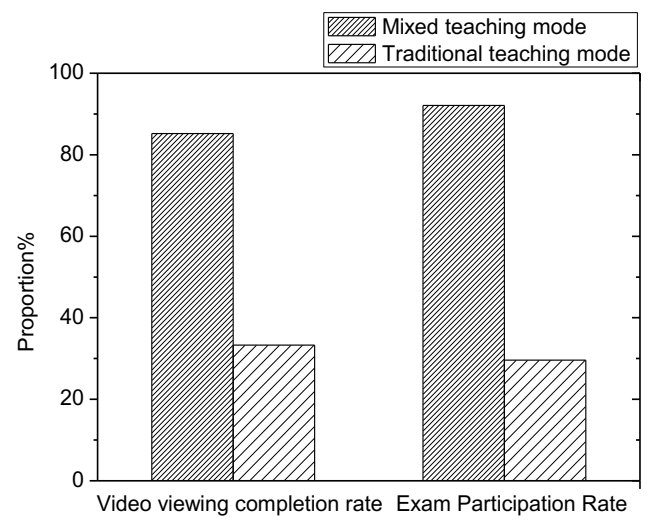

Fig. 9. Statistics of video-watching completion rate and exam participation rate of students under the two teaching modes 
Figure 9 shows the online video-watching completion rate and examination participation rate of students under the two teaching modes, and Figure 10 shows the average number of visits to the online platform. According to the figures, compared with the traditional teaching mode, the video-watching completion rate, examination participation rate, and average number of visits of students to the online platform under the blended teaching mode are much higher, indicating that under the blended teaching mode, students are more likely to participate in the learning of online resources, and students' learning initiative and enthusiasm have been improved.

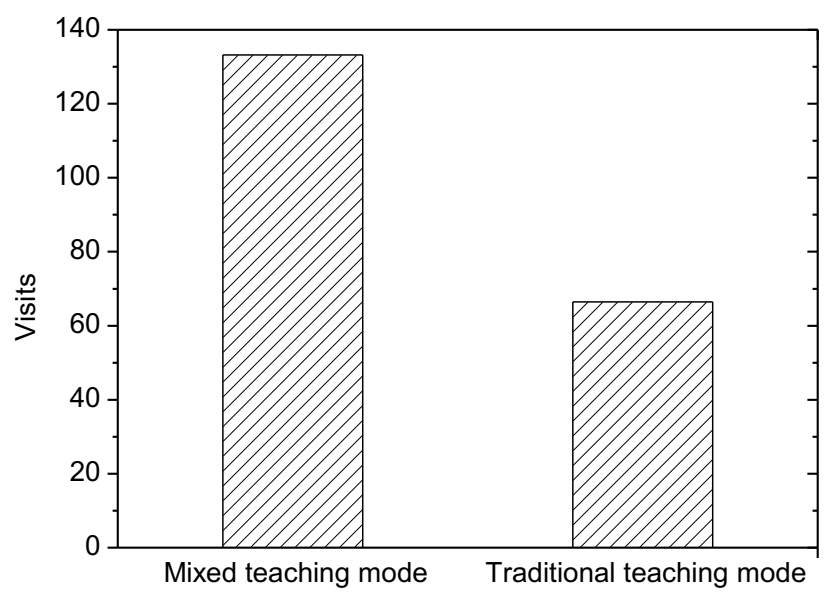

Fig. 10.Statistics of average number of visits to online platforms under the two teaching modes

\subsection{Analysis of student learning effect}

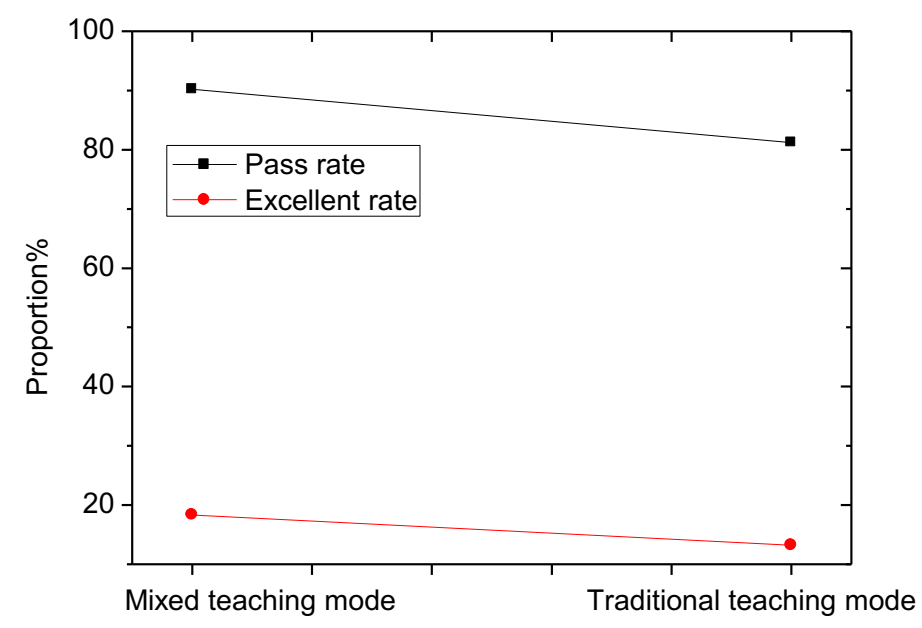

Fig. 11.Exam pass rate and excellent rate under the two teaching modes 
Figure 11 shows the statistics of students' course examination pass rate and excellent rate under the two teaching modes. Table 3 shows the statistics of the average scores of students in the final exams under the two teaching modes. According to the figure and the table, compared with the traditional teaching mode, students' average score, pass rate, and excellent rate are all higher, indicating that the implementation of the blended teaching mode has a certain promotive effect on improving the teaching effect and the students' learning level.

Table 3. Average scores of students in final exams under the two teaching modes

\begin{tabular}{|l|c|}
\hline \multicolumn{1}{|c|}{ Teaching mode } & The average score (points) \\
\hline Blended teaching mode & 83.2 \\
\hline Traditional teaching mode & 71.1 \\
\hline
\end{tabular}

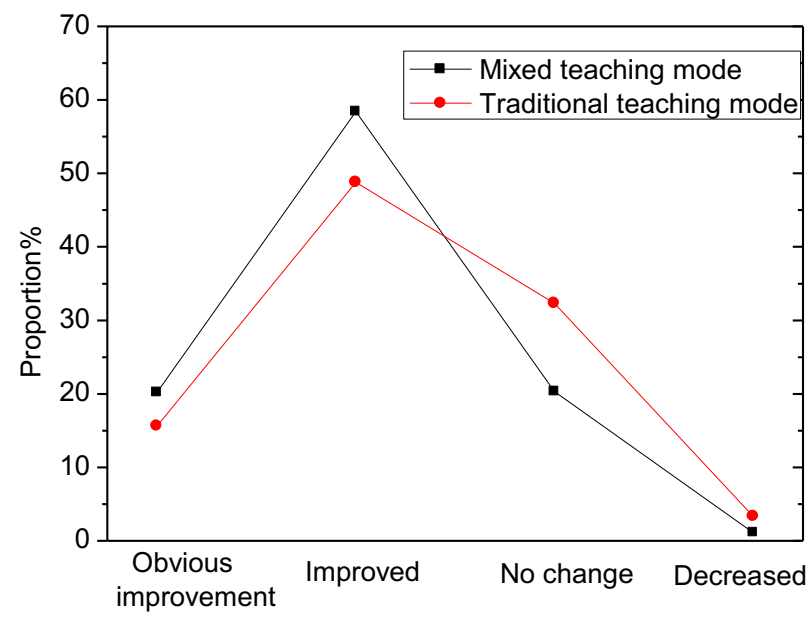

Fig. 12.Improvement of students' knowledge and ability

Figure 12 shows the survey results of the improvement of students' knowledge and ability under the two teaching modes. It can be seen from the figure that under the traditional teaching mode and the blended teaching mode, the number of students who think that their knowledge and ability have been improved accounted for $64.4 \%$ of the total number of surveyed students, and the number of students who think that their knowledge and ability have been significantly improved accounted for $78.6 \%$, indicating that the blended teaching mode has a promotive role in improving students' knowledge and ability.

\section{Conclusion}

The blended teaching mode is an inevitable trend of education reform. For any teaching mode, the ultimate goal is to increase students' participation in teaching and improve the teaching effect. For this purpose, from the perspective of students' learn- 
ing behaviour, this paper researched a novel blended teaching mode for management courses based on learning behaviour analysis, and drew the following conclusions:

1. The survey results of college students' learning behaviour and their requirements for blended teaching mode showed that, students have not formed the learning habits of pre-class preview and after-class review; most students have the awareness and ability to utilize Internet information resources to solve problems; most students are willing to adopt the blended teaching mode; and students hope that teachers can provide teaching resources such as videos and electronic documents.

2. This paper elaborated on the four constituent elements of blended teaching mode and constructed a blended teaching mode evaluation index system from two dimensions of process evaluation and result evaluation according to the characteristics of blended teaching mode.

3. Based on the constituent elements of the blended teaching mode and the survey results of students' learning behaviour, this paper designed a blended teaching mode for management courses, and divided the mode into three stages: before-class, inclass, and after-class; and introduced the online and offline teaching activities of teachers and students in the three stages in details.

4. From two aspects of student learning behaviour and learning effect, the application effect of the traditional teaching mode and the blended teaching mode was compared and analysed, and the results showed that compared with the traditional teaching mode, the blended teaching mode can increase students' participation in learning and improve the teaching effect, and it is helpful for students to improve their knowledge and comprehensive ability.

\section{$6 \quad$ References}

[1] Wang, L., Huang, Y., Omar, M.K. (2020). Analysis of Blended Learning Model Application Using Text Mining Method, International Journal of Emerging Technologies in Learning, 16(1): 172-187. https://doi.org/10.3991/IJET.V16I01.19823

[2] Indriyanti, N.Y., Yamtinah, S. (2020). An Inquiry into Students' Metacognition and Learning Achievement in a Blended Learning Design, International Journal of Emerging Technologies in Learning, 15(21): 77-88. https://doi.org/10.3991/ijet.v15i21.12907

[3] Jokinen, P., Mikkonen, I. (2013). Teachers' experiences of teaching in a blended learning environment. Nurse education in practice, 13(6): 524-528. https://doi.org/10.1016/j.nepr. 2013.03.014

[4] Yang, S. (2019). Research and countermeasure of network education teaching based on online learning behavior data analysis. Journal of Physics: Conference Series, 1237(2): 022054. https://doi.org/10.1088/1742-6596/1237/2/022054

[5] Hu, Z. (2020). Research and practice on the teaching mode of course project-Take the "credit rating" course as an example. The International Journal of Electrical Engineering \& Education, 0020720920928546. https://doi.org/10.1177/0020720920928546

[6] Meng, X., Chen, W., Liao, L., Li, T., Bai, S. (2019). Analysis of the teaching effect of the normal human morphology with mixed teaching mode and formative evaluation in China. International Journal of Morphology, 37(3): 1085-1088. https://doi.org/10.4067/s0717$\underline{95022019000301085}$ 
[7] Cobb, K.A., Brown, G., Hammond, R., Mossop, L.H. (2015). Students' perceptions of the Script Concordance Test and its impact on their learning behavior: a mixed methods study. Journal of veterinary medical education, 42(1): 45-52. https://doi.org/10.3138/jvme.0514$\underline{057 R 1}$

[8] Wandzilak, T., Bonnstetter, R.J., Mortensen, L.L. (1994). Examining congruence among teaching objectives, classroom behavior, and student learning: Feedback for university professors. Journal of Teaching in Physical Education, 13(3): 260-273. https://doi.org/ $\underline{10.1123 / \text { itpe. } 13.3 .260}$

[9] Tynan, B., Ryan, Y., Lamont-Mills, A. (2015). Examining workload models in online and blended teaching. British Journal of Educational Technology, 46(1): 5-15. https://doi. org/10.1111/bjet.12111

[10] Van Doorn, J.R., Van Doorn, J.D. (2014). The quest for knowledge transfer efficacy: blended teaching, online and in-class, with consideration of learning typologies for nontraditional and traditional students. Frontiers in psychology, 5: 324. https://doi.org/10.33 89/fpsyg.2014.00324

[11] Chang, N., Wang, Z., Hsu, S. H. (2020). A Comparison of the Learning Outcomes for a PBL-based Information Literacy Course in Three Different Innovative Teaching Environments. Libri, 70(3): 213-225. https://doi.org/10.1515/libri-2018-0132

[12] Kember, D., McNaught, C., Chong, F.C., Lam, P., Cheng, K.F. (2010). Understanding the ways in which design features of educational websites impact upon student learning outcomes in blended learning environments. Computers \& Education, 55(3): 1183-1192. https://doi.org/10.1016/j.compedu.2010.05.015

[13] Mary, S., Julie, J., Jennifer, G. (2014). Teaching evidence based practice and research through blended learning to undergraduate midwifery students from a practice based perspective. Nurse Education in Practice, 14(2): 220-224. https://doi.org/10.1016/j.ne pr.2013.10.001

[14] Williams, B. (2009). Do undergraduate paramedic students embrace case based learning using a blended teaching approach? A 3-year review. Australasian Journal of Educational Technology, 25(3): 421-439. https://doi.org/10.14742/ajet.1143

[15] Shen, C. (2018). MOOC Teaching Mode of News Transmission Based on Network Audio Data Decoding Technology. International Journal of Emerging Technologies in Learning (iJET), 13(6): 43-55. https://doi.org/10.3991/ijet.v13i06.8582

[16] Yang, C. (2018). Research on the Mixed Teaching Mode of TPACK in Software Testing Course. Recent Patents on Computer Science, 11(4): 302-311. https://doi.org/10.2174 $\underline{2213275911666181011150237}$

\section{Author}

Yang Liu received the master's degree in business management from Chongqing University, China, in 2008. Since2008, she has devoted herself to the teaching and research of vocational education. Until now, she has presided over four related projects and published several papers on Cultivation of College Students' innovative ability and blended learning. Her research interest includes Cultivation of College Students' innovative ability and blended learning. E-mail: Kris ocean $@$, 163.com

Article submitted 2021-02-19. Resubmitted 2021-03-20. Final acceptance 2021-03-22. Final version published as submitted by the authors. 